\title{
A New Species of the Genus Anatemnus (Pseudoscorpiones, Atemnidae) from China
}

\author{
Jun-Fang Hu and Feng Zhang \\ College of Life Sciences, Hebei University, Hebei, Baoding 071002, China \\ Correspondence should be addressed to Feng Zhang, dudu06042001@163.com \\ Received 5 December 2011; Accepted 25 December 2011 \\ Academic Editors: C. L. Frank and C. P. Wheater
}

Copyright ( $) 2012$ J.-F. Hu and F. Zhang. This is an open access article distributed under the Creative Commons Attribution License, which permits unrestricted use, distribution, and reproduction in any medium, provided the original work is properly cited.

One new species belonging to Anatemnus Beier is reported from China under the name A. chaozhouensis sp. nov.

\section{Introduction}

The pseudoscorpions genus Anatemnus belongs to subfamily Atemninae, family Atemnidae. It was erected by Beier in 1932 for the type species Chelifer javanus Thorell, 1883. This genus includes 18 known species which are widespread in Africa, Americas, and Asia. Most of them (11 species) distribute in Southeast Asia, and only one species, A. orites Thorell [1], was recorded from China $[2,3]$.

Anatemnus is characterized by the trichobothrial pattern of fixed chelal finger: the distance trichobothrium it from fingertip equals that of ist and isb, distance between est and $e s b$ is longer than that of ist and isb; pedipalpal patella expands not obviously and nearly oval [4].

Among the pseudoscorpions collected from Dong'an Town, Chaozhou City, Guangdong Province in the summer of 2011, we found one Anatemnus species new to science and described it here as A. chaozhouensis sp. nov.

\section{Materials and Methods}

The material was preserved in $75 \%$ alcohol. The patterns of description and terminology follow $[5,6]$. Terminology of genitalia follows [7]. All measurements are given in millimeters. Drawings were made with the aid of a prism mounted above the eyepiece of a compound microscope. Photographs were taken with a Leica M165 stereomicroscope. Detailed examination was carried out with a Nikon YS100 general optical microscope. Temporary slide mounts were made in glycerol.

The following abbreviations are used in the text for trichobothria-b: basal; sb: sub-basal; st: sub-terminal; t: terminal; ib: interior basal; isb: interior sub-basal; ist: interior sub-terminal; it: interior terminal; eb: exterior basal; esb: exterior sub-basal; est: exterior sub-terminal; et: exterior terminal. The following abbreviations are used in the text for male genitalia-A: lateral apodeme; B: hooked branch; C: sclerotized bar; D: longitudinal fold of medial diverticulum; E: ejaculatory canal atrium; F: lateral rods; G: dorsal apodeme; H: ventral diverticulum; L: lateral lip of lateral apodeme. The specimens referred here are deposited in the Museum of Hebei University (MHBU), Baoding City, China.

\section{Taxonomy}

3.1. Anatemnus Chaozhouensis sp. nov. (Figures 1 and 2).

3.1.1. Type Material. Holotype male (Ps.-MHBU-GD11072201), China, Guangdong Province, Chaozhou City, Dong'an Town [23.46 ${ }^{\circ} \mathrm{N}, 116.68^{\circ} \mathrm{E}$ ], 22 July 2011, Feng Zhang leg. Paratypes: five males (Ps.-MHBU-GD11072202-11072206) and three females (Ps.-MHBU-GD11072207-11072209), data same as for holotype.

3.1.2. Diagnosis. This new species is characteristic by: carapace with two distinct developed eyespots; color of carapace, pedipalp, tergite XI and sternite XI dark brown 


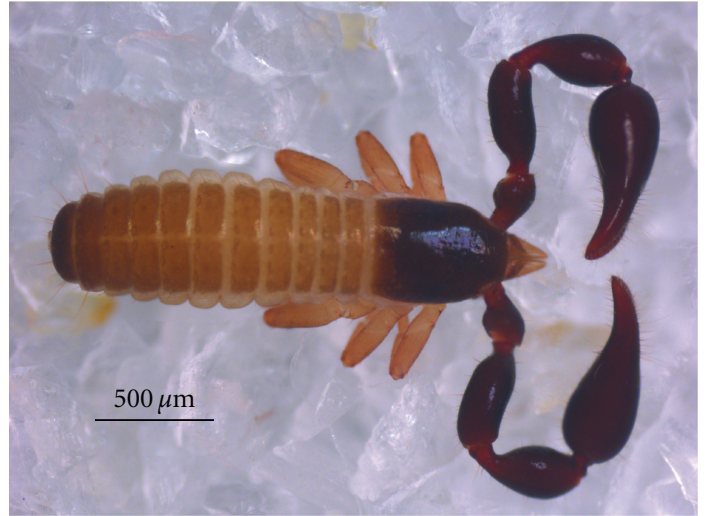

FIgURe 1: Anatemnus chaozhouensis sp. nov.: male habitus, dorsal view.

(Figure 1); pedipalpal femur with a few fine granules interiorly; trochanter with a round dorsal tubercle.

\subsubsection{Etymology. The specific name refers to the type local-} ity.

3.1.4. Description. Setae of body straight and dentate apically; carapace, pedipalp, tergite XI, and sternite XI dark brown in both males and females (Figure 1).

Carapace (Figure 2(a)) smooth and with two distinct and slightly raised eyespots, without transverse furrow, 32 setae in total, of which 4 at anterior margin and 6 at posterior margin.

Abdomen tergites VI-IX completely divided and other tergites incompletely divided; tergal chaetotaxy: 6: 6: 6: 6-7: 8: 7-9: 8-10: 8-10: 8: 7-8 (4T): 8 (2T): 2; sternal chaetotaxy (IV-XI): 6-8: 10: 10: 10: 8-10: 8-9: 6 (4T): 7-10 (4T): 2; male anterior genital operculum (Figure $2(\mathrm{~h})$ ) with 6 setae on each side; posterior genital sternite with 6 setae. Male genital structure (Figure 2(i)): the distal part of lateral apodemes (L) with a strongly curved medial border and ending in a small projecting snout at the distalmost end, and the proximal part of lateral apodemes, namely, the hooked branch (B) is comparatively small; the longitudinal fold of medial diverticula (D) has a projection midway along its length; the ejaculatory canal atrium (E) crescent-shaped on either side and the distal end of the atrium is procurved; the lateral rods (F) long and running parallel to the sagittal line, diverging proximally; the tip of dorsal apodeme $(G)$ completely joined; the ventral diverticulum $(\mathrm{H})$ bilobed. Pleural membrane with fine longitudinal stripes. Female: tergal chaetotaxy: 9-10: 10: 10: 9-12: 12-14: 13-14: 1314: 14-15: 14: 11-12 (4T): 10-12 (2T):2, tergites VI-IX completely divided and other tergites incompletely divided; sternal chaetotaxy (IV-XI): 10-12: 12-14: 13-14: 14: 12-14: 12-14: $12-13$ (4T): 8-9 (4T): 2; genital area (Figure $2(\mathrm{k})$ ): sternite II with 10-12 setae and sternite III with 8 setae on the posterior margin; female genital structure (Figure $2(j)$ ) simple, spermathecae present, and provided with separated median cribriform plates.

Cheliceral palm (Figure 2(b)) with 4 setae, setae bs and es dentate apically, is and $l s$ long and acute, movable finger with a galeal seta; fixed finger with 3 small and 4 large retrorse teeth, movable finger with 1 or 2 large teeth and a long broadly rounded subapical lobe; male galea (Figure 2(d)) slender and apically with 5 dentations; female galea (Figure $2(\mathrm{~g})$ ) long with 4 branchelets and the middle two branchelets rebranching into two; rallum (Figure 2(c)) composed of 4 setae, of which the distal one anteriorly dentated; serrula exterior 20 lamellae, serrula interior 9 or 10 lamellae.

Pedipalps (Figure 2(f)) dark reddish, only femur with granules interiorly; trochanter with a round dorsal tubercle, patella pedicel slender; fixed finger (Figure 2(e)) with about 32-34 pointed teeth of equal length, movable finger with about 35-42 teeth; trichobothrial pattern: st situated midway between $s b$ and $t$, it of fixed finger well removed from the finger tip and distance from finger tip equal to the distance between ist and isb, distance between esb and est longer than that of $i s b$ and ist.

Leg IV with one tactile seta at the base of tarsus (Figure 2(l)) (TS = 0.16-0.21).

3.1.5. Dimensions (Length/Breadth or Depth, in $\mathrm{mm}$ ). Male. Body length 2.55-2.75. Carapace 0.33-0.35/0.26-0.29 (1.211.27). Pedipalp: trochanter $0.30-0.375 / 0.215-0.225$ (1.401.67), femur $0.565-0.60 / 0.225-0.24$ (2.50-2.51), patella $0.60-0.64 / 0.265-0.29(2.21-2.26)$, chela (with pedicel) $1.02-$ $1.10 / 0.33-0.38$ (2.89-3.09), chela (without pedicel) $0.93-$ 1.02 (2.68-2.82), hand length (without pedicel) 0.500.55 (1.45-1.52), movable finger length 0.45-0.48 (0.870.90 times longer than length of hand without pedicel). Chelicera 0.25-0.275/0.125-0.15 (1.83-2.00), movable finger length $0.20-0.225$. Leg I: femur $0.20-0.215 / 0.14-0.15$ (1.42-1.43), patella $0.315-0.35 / 0.125-0.14$ (2.50-2.52), tibia $0.25-0.29 / 0.09-0.10(2.78-2.90)$, tarsus $0.275-0.30 / 0.06-$ 0.07 (4.29-4.58). Leg IV: femur + patella 0.525-0.60/0.1750.195 (3.00-3.08), tibia $0.40-0.44 / 0.11-0.115$ (3.64-3.83), tarsus 0.325-0.35/0.075-0.09 (3.89-4.33).

Female. Body length 3.50-3.95. Carapace 0.39-0.42/ 0.315-0.33 (1.24-1.27). Pedipalp: trochanter 0.35-0.40/ $0.20-0.22$ (1.75-1.78), femur 0.65-0.675/0.24-0.25 (2.702.71 ), patella $0.625-0.65 / 0.30-0.325(2.00-2.08)$, chela (with pedicel) 1.15-1.20/0.43-0.45 (2.66-2.67), chela (without pedicel) 1.05-1.12 (2.44-2.49), hand (without pedicel) $0.60-$ 0.65 (1.40-1.44), movable finger length 0.45-0.50 (0.750.77 times longer than hand without pedicel). Chelicera $0.30-0.32 / 0.16-0.18$, movable finger length $0.22-0.24$. Leg I: femur $0.215-0.225 / 0.14-0.16(1.41-1.54)$, patella $0.35-$ $0.36 / 0.125-0.15(2.40-2.80)$, tibia $0.315-0.325 / 0.10-0.125$ (2.60-3.20), tarsus 0.275-0.30/0.07-0.08 (3.75-3.93). Leg IV: femur + patella $0.615-0.675 / 0.21-0.225(2.93-3.00)$, tibia $0.46-0.475 / 0.125-0.14(3.39-3.68)$, tarsus $0.325-0.35 / 0.08-$ $0.09(3.89-4.06)$.

3.1.6. Distribution. China (Guangdong Province, Chaozhou City, Dong'an Town).

3.1.7. Habitat. According to field record, this new species is collected under the bark of the Olea europaea L. trees. 


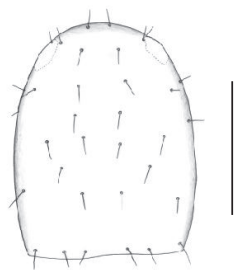

(a)

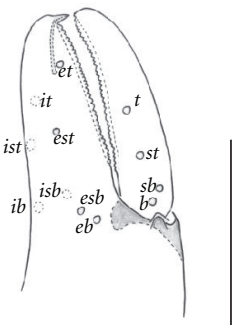

(e)

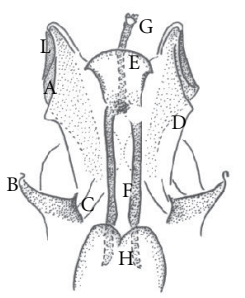

(i)

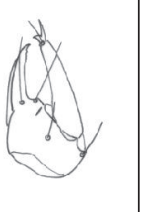

(b)

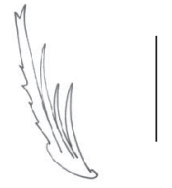

(c)

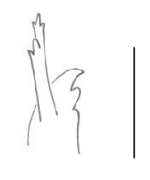

(d)

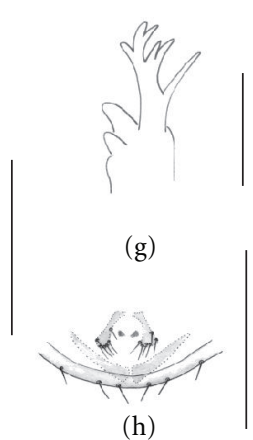

(f)

(h)

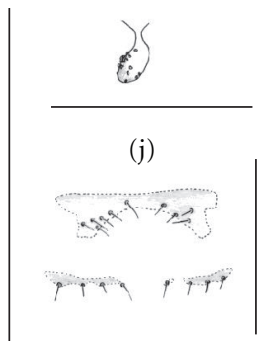

(k)

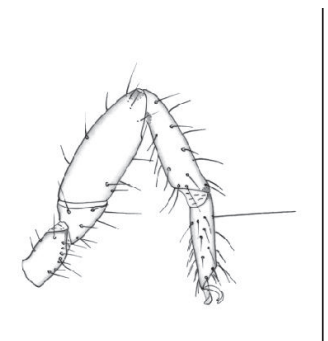

(1)

FIgURE 2: Anatemnus chaozhouensis sp. nov.: (a) male carapace, dorsal view; (b) male chelicerae, dorsal view; (c) rallum; (d) male galea; (e) male chelal fingers, lateral view; (f) male pedipalp, dorsal view; (g) female galea; (h) male genital area; (i) male genital; (j) spermathecae; (k) female genital area; (l) leg IV. Scale lines: $1.0 \mathrm{~mm}$ (f), $0.5 \mathrm{~mm}$ (l), $0.4 \mathrm{~mm}$ ((a), (b), (e), (h), and (i)-(k)), $0.05 \mathrm{~mm}((\mathrm{c}),(\mathrm{d})$, and (g)).

3.1.8. Remarks. This new species is similar to A. orites which is also distributed in China; however, it differs from the latter in having two distinct and slightly raised eyespots, while eyespots is indistinct in A. orites; slender chela (with pedicel 2.89-3.09 and without pedicel 2.68-2.82 times as long as broad versus 2.2 times in A. orites). This new species is also similar to A. angustus Redikorzev, 1938 distributed in Bhutan, India, Malaysia, and Vietnam, but it can be distinguished from the latter by that: pedipalpal trochanter with a round dorsal tubercle, while tubercle is coniform in A. angustus; only pedipalpal femur slightly granulated interiorly, while all of the pedipalp is with slightly dense granules in A. angustus; pedipalp is with consistent dark color, pedipalpal femur and patella are more bright than chela in A. angustus.

\section{Acknowledgments}

Many thanks are given to the two anonymous reviewers for their comments on the text. This paper was supported by the National Natural Science Foundation of China (Nos. 30970325, 31071885, 31093430).

\section{References}

[1] T. Thorell, "Aracnidi Artrogastri Birmani raccolti da L. Feanel 1885-1887," Annali del Museo Civico di Storia Naturale di Genova, vol. 7, no. 2, pp. 521-729, 1889.

[2] M. S. Harvey, "Pseudoscorpions of the World, version 2.0, Western Australian Museum," 2011, http://www.museum.wa .gov.au/catalogues/pseudoscorpions/.

[3] W. Schawaller, "Review of the pseudoscorpion fauna of China (Arachnida: Pseudoscorpionida)," Revue Suisse de Zoologie, vol. 102, no. 4, pp. 1045-1064, 1995.

[4] M. Beier, "Revision der Atemnidae (Pseudoscorpionidea). Zoologische Jahrbücher, Abteilung für Systematik," Ökologie und Geographie der Tiere, vol. 62, pp. 547-610, 1932.

[5] J. C. Chamberlin, "The arachnid order Chelonethida," Stanford University Publications, Biological Sciences, vol. 7, no. 1, pp. 1284, 1931.

[6] M. L. I. Judson, "A new and endangered species of the pseudoscorpion genus Lagynochthonius from a cave in Vietnam, with notes on chelal morphology and the composition of the Tyrannochthoniini (Arachnida, Chelonethi, Chthoniidae)," Zootaxa, no. 1627, pp. 53-68, 2007.

[7] F. E. Klausen, "The male genitalia of the family Atemnidae (Pseudoscorpiones)," Journal of Arachnology, vol. 33, no. 3, pp. 641-662, 2005. 

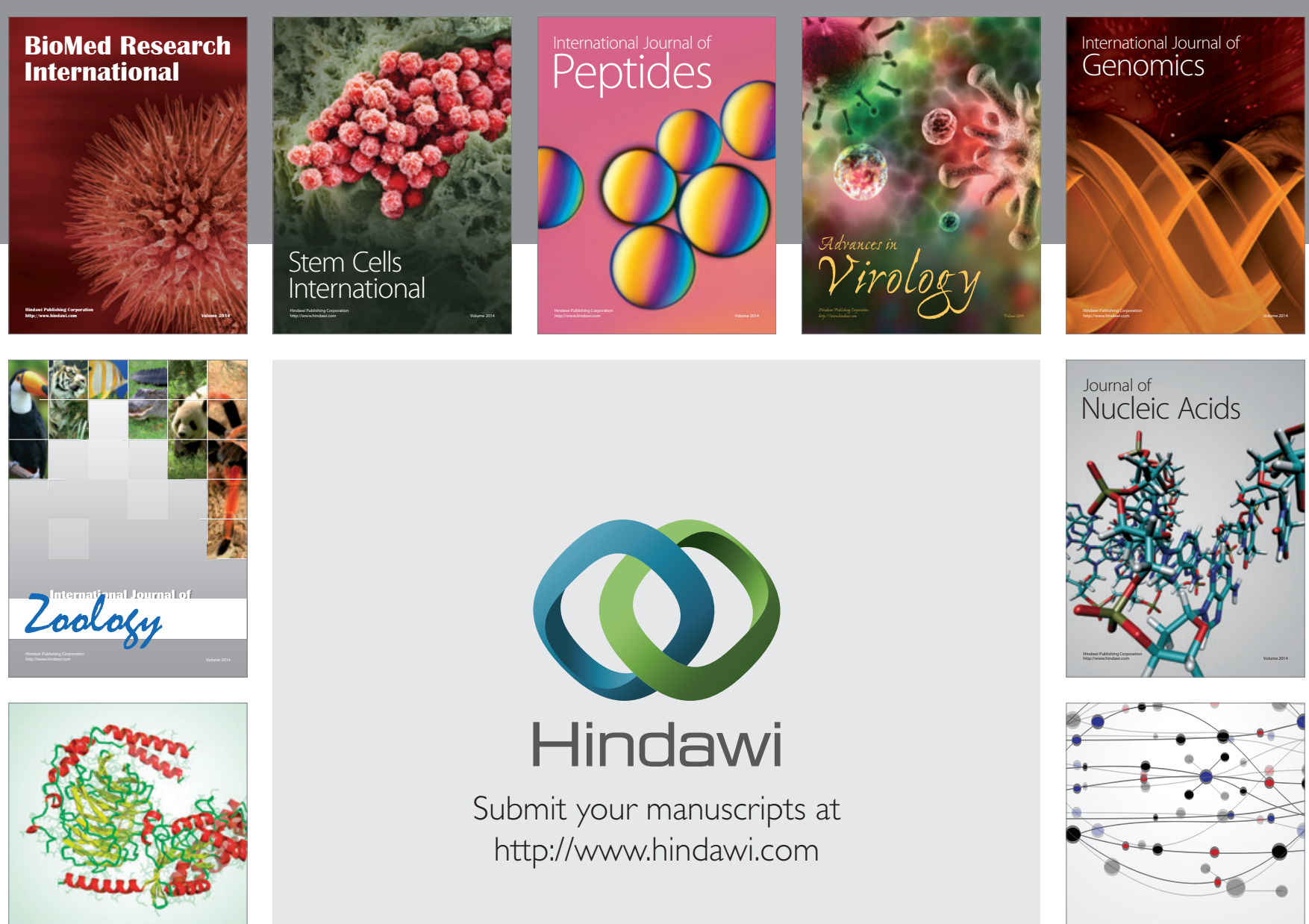

Submit your manuscripts at

http://www.hindawi.com

Signal ${ }^{\text {Jumal }}$ Transduction
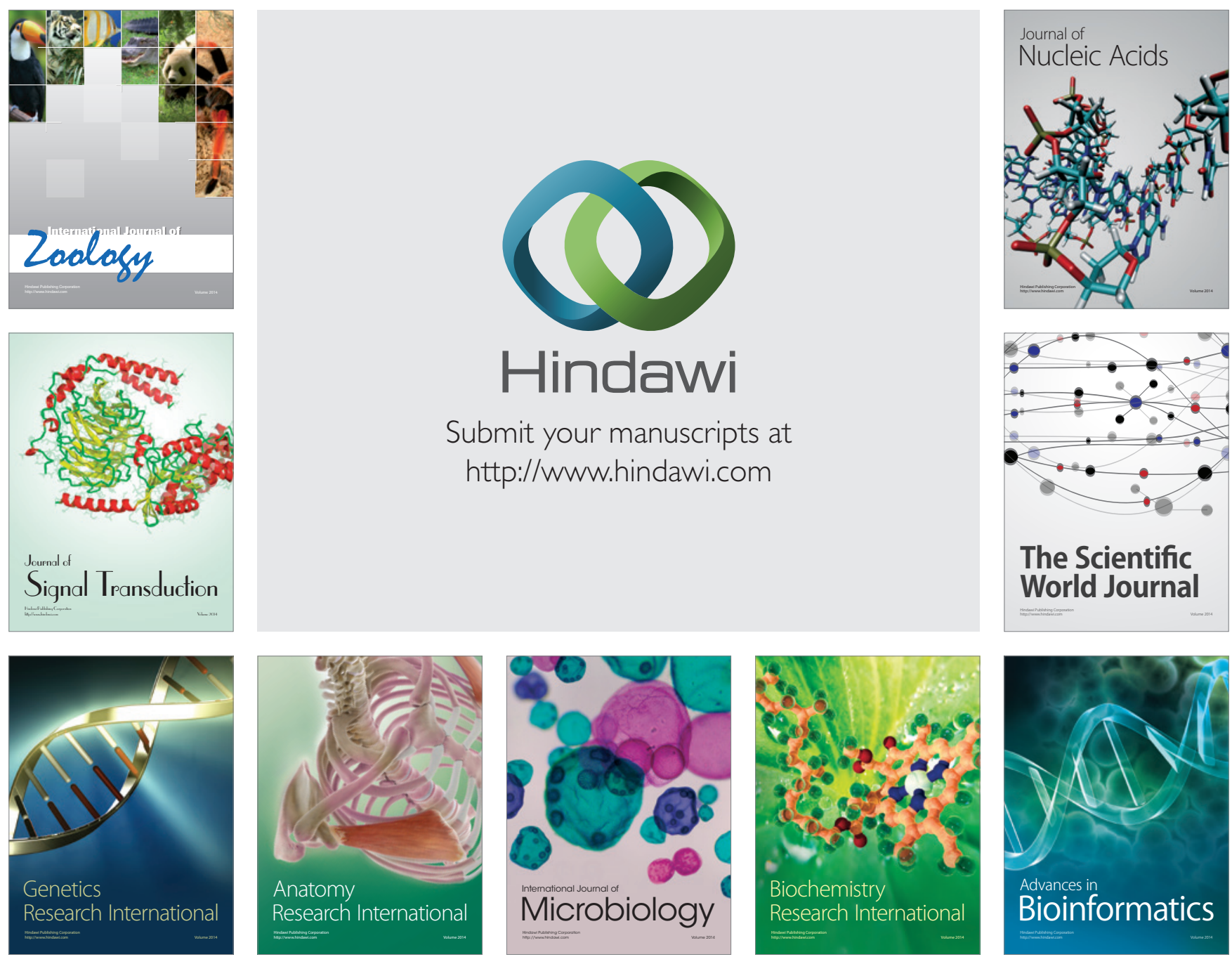

The Scientific World Journal
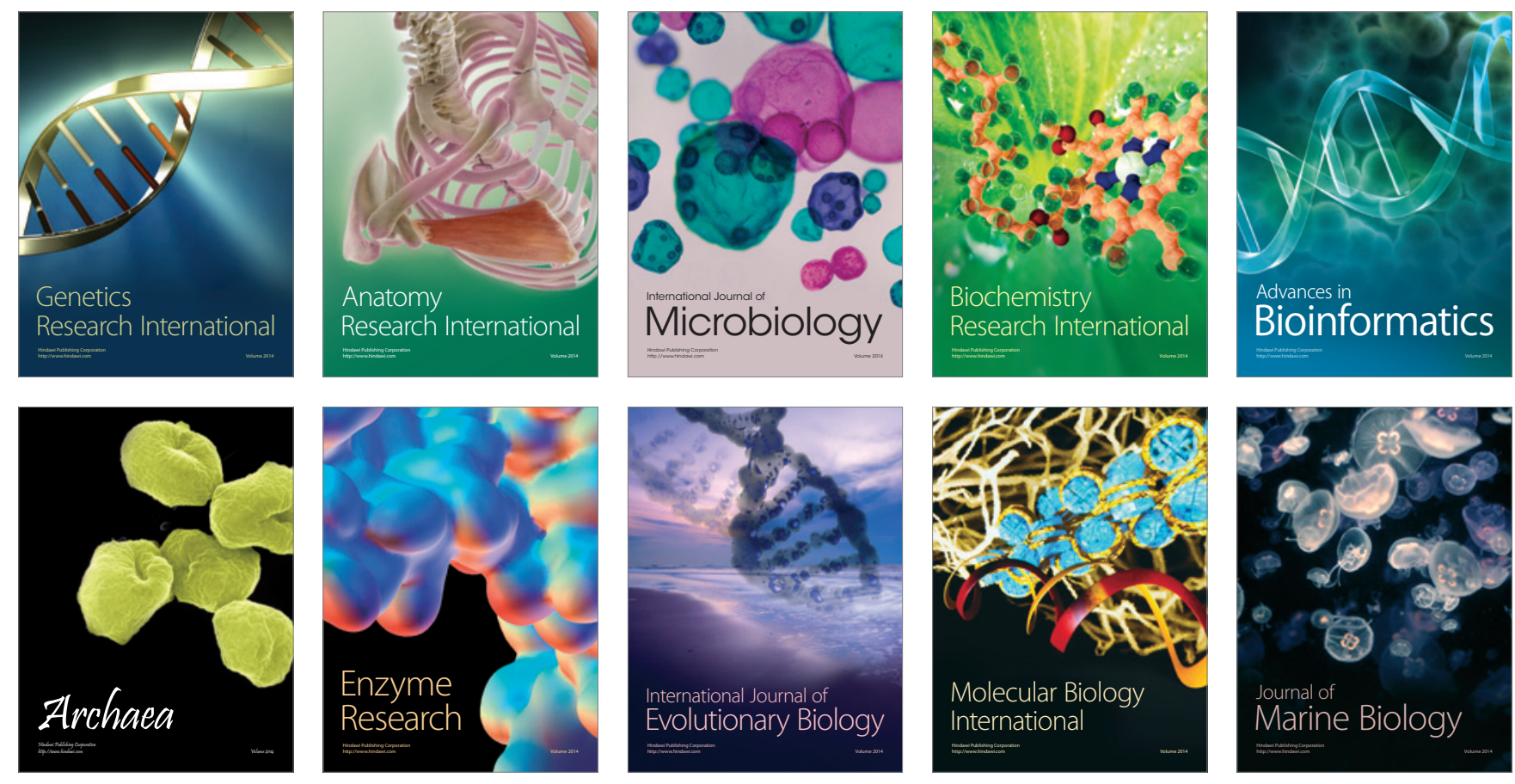